\title{
PENGARUH REWARD DAN PUNISHMENT TERHADAP KINERJA KARYAWAN PT GLENMORE AGUNG NUSANTARA
}

\author{
Dewi Nuzila Ramadanita, Edi Suswardji Nugroho dan Dede Jajang Suyaman \\ Univeristas Singaperbangsa Karawang, Jawa Barat, Indonesia. \\ Email: 1910632020010@student.unsika.ac.id, edisus.nugroho@fe.unsika.ac.id dan \\ jajang@fe.unsika.ac.id
}

\section{Abstract}

The purpose of this study was to determine the effect of reward, punishments on employee performance at PT. Glenmore Agung Nusantara. The population used is saturated sampling where all employees are sampled, amounting to 54 people. The research was conducted by distributing questionnaires and using ordinal measurement levels with a numerical scale. The test of this research is the t test, $f$ test, and multiple linear regression. The results showed that there was a positive and significant influence between reward and punishment variables simultaneously on the performance variable of the Fcount value of 9677.706 and the Ftable value of 3.17. The $t$ test result shows that the reward variable has a positive and significant effect on the performance variable with a value ratio of 3,448>1,675. And the punishment variable has a positive and significant influence on the performance variable with a value ratio of 11,191>1,675.

Keywords: Reward; Punishment; Performance

\begin{abstract}
Abstrak
Tujuan penelitian ini adalah untuk mengetahui pengaruh Reward, Punishment terhadap kinerja karyawan pada PT. Glenmore Agung Nusantara. Populasi yang digunakan adalah sampling jenuh dimana seluruh karyawan dijadikan sampel yang berjumlah 54 orang. Penelitian dilakukan dengan menyebar kuesioner dan menggunakan aras pengukuran ordinal dengan skala numerical. Pengujian penelitian ini adalah uji t, uji f, dan uji regresi linier berganda. Hasil penelitian menunjukkan bahwa adanya pengaruh yang positif dan signifikan antara variabel reward dan punishment secara simultan terhadap variabel kinerja dari nilai $\mathrm{F}_{\text {hitung }}$ sebesar 9677,706 dan nilai $F_{\text {tabel }}$ sebesar 3,17. Hasil uji t adalah variabel reward mempunyai pengaruh yang positif dan signifikan terhadap variabel kinerja dengan perbandingan nilai sebesar 3,448 > 1,675. Dan variabel punishment mempunyai pengaruh yang positif dan signifikan terhadap variabel Kinerja dengan perbandingan nilai sebesar $11,191>1,675$.
\end{abstract}

Kata kunci: reward; punishment; kinerja 
Coresponden Author

Email: 1910632020010@ student.unsika.ac.id Artikel dengan akses terbuka dibawah lisensi

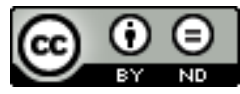

\section{Pendahuluan}

Organisasi yang bergerak di bidang produksi dan jasa akan berusaha mencapai tujuan atau target yang telah direncanakan sebelumnya ketika melaksanakan kegiatan. Yang terpenting, keberhasilan berbagai proses perusahaan dalam mencapai tujuannya tidak hanya bergantung pada keunggulan teknologi, tetapi juga keunggulan sarana dan prasarana, serta sumber daya manusianya. Perusahaan sendiri perlu menghasilkan sumber daya manusia yang berkinerja tinggi untuk pengembangan bisnis. Manajemen sumber daya manusia merupakan sarana yang dirancang untuk mempengaruhi kinerja, perilaku dan sikap karyawan sehingga dapat memberikan kontribusi yang terbaik bagi terwujudnya tujuan internal perusahaan (Suparyadi, 2015). Faktor sumber daya manusia merupakan aspek yang harus diperhatikan oleh perusahaan, daya saing yang tinggi akan memotivasi setiap perusahaan untuk mempertahankan kelangsungan hidup perusahaan.

Sumber daya manusia yang profesional dan berkualitas pasti akan menghasilkan kinerja berdasarkan tugas yang diberikan, dan kinerja pribadi diartikan sebagai kemampuan seseorang untuk memiliki pengetahuan profesional tertentu. Sesuaikan sudut pandang ini, Stephen Robbins dalam (Suyanto, 2018) mengemukakan bahwa kineja diartikan sebagai hasil dari evaluasi terhadap pekerjaan yang dilakukan individu dibandingkan dengan kriteria yang telah ditetapkan.

Salah satu cara yang dapat digunakan untuk meningkatkan kualitas sumber daya manusia adalah dengan pemberian reward and punishments. Imbalan diberikan oleh perusahaan kepada karyawan dan digunakan sebagai umpan balik informasi tentang kinerja atau kontribusi karyawan kepada perusahaan. Dan hukuman merupakan akibat negatif dari akibat buruk bagi karyawan. Penghargaan tersebut untuk memotivasi karyawan agar dapat mendorong karyawan untuk berprestasi lebih baik (Soetjipto, 2017)

Tentunya agar karyawan dapat bekerja sebaik-baiknya, karyawan harus memiliki motivasi yang tinggi, baik itu motivasi internal maupun motivasi eksternal. Motivasi adalah proses atau dorongan dari tindakan internal atau eksternal individu yang akan mempengaruhi perilaku individu dalam mencapai tujuan (Suharyat, 2009). Tanpa motivasi kerja yang memadai, karyawan akan cenderung dipaksa bekerja, sehingga hasilnya tidak sesuai dengan harapan perusahaan. Pernyataan tersebut juga sejalan dengan penelitian yang dilakukan oleh Endang Mahpudin dan Pupung Purnamasari (Febianti, 2018) dengan judul Pengaruh Motivasi terhadap Kinerja Karyawan Pada PT. Bank Central Asia, Tbk. Cabang Karawang, dalam penelitiannya mengatakan bahwa terdapat hubungan yang signifikan antara variabel motivasi kerja dengan variabel kinerja karyawan. 
Pemberian motivasi secara tepat kepada karyawan akan mempengaruhi motivasinya, karena semangat kerja dan ketelitian karyawan dalam bekerja akan meningkat. Pernyataan tersebut juga sejalan dengan penelitian yang dilakukan oleh (Wulandari, Manullang, \& Panjaitan, 2019) dengan judul Pengaruh Reward dan Punishment terhadap Kinerja Karyawan PT Matsuzawa Pelita Funiture Indonesia yaitu untuk meningkatkan kinerja perusahaan dalam bidang sumber daya manusia memberikan reward dengan tujuan untuk memotivasi karyawan agar mencapai kinerja yang tinggi, sedangkan punishment diberikan untuk membentuk suatu karakteristik yang sifatnya positif guna mencegah karyawan bertindakan yang dapat merugikan perusahaan dan dapat meningkatkan kinerja karyawan.

Afiliasi adalah motivasi untuk moral. Oleh karena itu, kebutuhan akan hubungan kepemilikan merangsang semangat karyawan, karena setiap orang ingin diterima atau diapresiasi oleh orang lain di lingkungannya sendiri. Dengan kata lain, jika karyawan bekerja dengan baik, maka perusahaan harus memberikan penghargaan. Sebaliknya, jika seorang karyawan melakukan kesalahan yang tidak terduga dalam pekerjaannya, maka perusahaan berhak memberikan sanksi kepada karyawan tersebut agar hal tersebut tidak terulang kembali. Pernyataan ini juga sejalan dengan penelitian yang dilakukan oleh Rizki Ayu Pramesti (Chandra, 2020) dengan judul Pengaruh Reward dan Punishment terhadap Kinerja Karyawan KFC Artha Gading, hasil penelitiannya menyebutkan bahwa reward dan punishment berpengaruh positif dan signifikan terhadap kinerja karyawan.

Menurut penelitian (Pradnyani, Rahmawati, \& Suci, 2020) yang berjudul "Pengaruh reward and punishment terhadap motivasi kerja dan dampaknya terhadap kinerja karyawan PT. Difa Kreasi Cikarang”, penelitian ini bertujuan untuk mengetahui pengaruh reward and punishments $(\mathrm{X})$ dan motivasi (Y) terhadap kinerja (Z). Difa Kreasi. Hipotesis reward and punishment secara langsung maupun tidak langsung memiliki pengaruh yang signifikan terhadap kinerja karyawan melalui motivasi kerja. Sampel penelitian berjumlah 106 karyawan, karena sampel terlalu kecil maka dipilih seluruh karyawan PT dan Difa Kreasi. Teknik analisis yang digunakan dalam penelitian ini adalah persamaan struktural PLS (Partial Least Squares). Dari hasil penelitian dapat disimpulkan bahwa reward and punishments berpengaruh positif dan signifikan terhadap variabel motivasi kerja. Hal ini dapat menunjukkan bahwa semakin efektif reward and punishment maka semakin kuat pula tingkat motivasi kerja karyawan PT. Difa Kreasi.

Menurut penelitian (Nelizulfa, 2018) yang berjudul "Pengaruh Penghargaan dan Motivasi Terhadap Kinerja Karyawan (Studi Pada Divisi Penjualan PT. United Motors Center Suzuki Ahmad Yani, Surabaya)" "Penelitian tersebut bertujuan untuk mengetahui pengaruh penghargaan dan motivasi terhadap kinerja karyawan PT. United Motors Center Suzuki ahmad Yani pada divisi penjualan. Sampel penelitian sebanyak 70 karyawan yang diambil dari seluruh karyawan pada divisi penjualan. Metode penelitian yang digunakan pada penelitian tersebut adalah regresi linear berganda. Hasil yang didapat dari penelitian adalah terdapat pengaruh yang positif dan signifikan antara 
variabel penghargaan dan motivasi terhadap kinerja karyawan pada divisi penjualan kerja PT. United Motors Center Suzuki Ahmad Yani.

PT Glenmore Agung Nusantara merupakan perusahaan yang berlokasi di Kabupaten Karawang yang bergerak di bidang jasa pengangkutan limbah B3. Pengangkutan limbah B3 adalah kegiatan pengangkutan, pemindahan dan pengiriman. Pengiriman limbah B3 akan dikirim dari peserta pengelola limbah B3 ke peserta pengelola limbah B3 lainnya. Pelaku adalah pengumpul, pengguna, penghasil, TPA, dan pembuang limbah B3. Apabila produsen telah bekerjasama dengan kontrak pengelolaan limbah B3 untuk menentukan tujuan akhir pengelola limbah B3, maka pengangkutan limbah B3 akan dilakukan. Pemindahan limbah B3 dari satu lokasi pengelolaan ke lokasi pengelolaan lain harus mendapat izin khusus. Izin tersebut diperoleh dari Dirjen Perhubungan dan disertai rekomendasi pengangkutan limbah B3 yang dibuat oleh Kementerian Lingkungan Hidup (KLH).

Berdasarkan hasil observasi yang dilakukan penulis, ditemukan adanya beberapa indikasi yang menunjukkan hambatan kinerja karyawan PT Glenmore Agung Nusantara. Berikut adalah tabel penilaian kinerja karyawan tahun 2018-2020:

Tabel 1

Rekapitulasi Hasil Penilaian Kerja Karyawan

PT Glenmore Agung Nusantara tahun 2018-2020

\begin{tabular}{cccccccc}
\hline Bobot & Predikat & $\mathbf{2 0 1 8}$ & Presentase & $\mathbf{2 0 1 9}$ & Presentase & 2020 & Presentase \\
\hline$<32$ & Buruk & $\mathbf{0}$ & $\mathbf{0}$ & $\mathbf{0}$ & $\mathbf{0}$ & $\mathbf{0}$ & $\mathbf{0}$ \\
\hline $\mathbf{3 3 - 4 8}$ & Kurang & $\mathbf{2}$ & $\mathbf{1 , 9}$ & $\mathbf{4}$ & $\mathbf{3 , 8}$ & $\mathbf{5}$ & $\mathbf{4 , 7}$ \\
\hline $\mathbf{4 9 - 6 4}$ & Cukup & $\mathbf{2 4}$ & $\mathbf{2 2 , 6}$ & $\mathbf{2 7}$ & $\mathbf{2 5 , 5}$ & $\mathbf{2 9}$ & $\mathbf{2 7 , 4}$ \\
\hline $\mathbf{6 5 - 8 0}$ & Baik & $\mathbf{6 3}$ & $\mathbf{5 9 , 4}$ & $\mathbf{6 0}$ & $\mathbf{5 6 , 6}$ & $\mathbf{5 8}$ & $\mathbf{5 4 , 7}$ \\
\hline $\begin{array}{c}\mathbf{8 1 -} \\
\mathbf{1 0 0}\end{array}$ & $\begin{array}{c}\text { Sangat } \\
\text { Baik }\end{array}$ & 17 & 16 & 15 & 14,2 & 14 & 13,2 \\
\hline $\begin{array}{c}\text { Jumlah } \\
\text { Karyawan }\end{array}$ & 106 & 100 & 106 & 100 & 106 & 100 \\
\hline
\end{tabular}

Sumber: Bagian SDM PT Glenmore Agung Nusantara

Seperti terlihat dari tabel ringkasan evaluasi kerja karyawan PT Glenmore Agung Nusantara di atas, dari tahun 2018 hingga tahun 2020 evaluasi kinerja pada tahun 2020 mengalami penurunan. Sejak tahun 2018 jumlah pegawai dengan predikat baik dan predikat baik semakin berkurang, sebaliknya pegawai dengan predikat cukup dan predikat lebih kecil selalu meningkat. Pada tahun 2020, peringkat baik karyawan akan menjadi $54,7 \%$ dan sangat baik $13,2 \%$. Sedangkan proporsi pegawai dengan predikat cukup adalah 27,4\%, lebih rendah dari 4,7\%.

Berikut merupakan informasi mengenai beberapa masalah yang terjadi pada PTGlemore Agung Nusantara: 


\section{Tabel 2}

\section{Hambatan Kinerja Karyawan PT Glenmore Agung Nusantara}

\begin{tabular}{|c|c|}
\hline Hambatan & Presentase \\
\hline $\begin{array}{lcr}\text { Kinerja } & \text { karyawan } & \text { dengan } \\
\text { predikat } & \text { baik } & \text { setiap } \\
\text { tahunnya menurun } & \\
\end{array}$ & $(22 \%)$ \\
\hline $\begin{array}{l}\text { Sebagian karyawan belum } \\
\text { mampu menyelesaikan tugas } \\
\text { dengan cepat dan tepat } \\
\text { waktu sehingga target tidak } \\
\text { tercapai }\end{array}$ & $(21 \%)$ \\
\hline 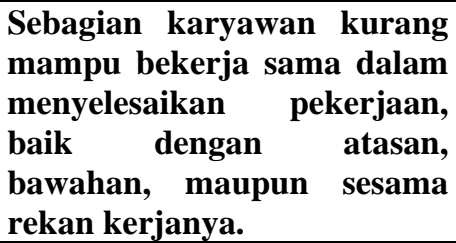 & $(25 \%)$ \\
\hline
\end{tabular}

Sumber: PT Glenmore Agung Nusantara

Tabel 3

Pemberian Reward Karyawan PT Glenmore Agung Nusantara

\begin{tabular}{lc}
\hline \multicolumn{1}{c}{ Reward } & Presentase \\
\hline $\begin{array}{l}\text { Bonus finansial diluar } \\
\text { gaji pokok }\end{array}$ & $(23 \%)$ \\
\hline Rekreasi dan hiburan & $(23 \%)$ \\
\hline
\end{tabular}

Sumber: PT Glenmore Agung Nusantara

Tabel 4

\section{Pemberian Punishment Karyawan PT Glenmore Agung Nusantara}

\begin{tabular}{lc}
\hline \multicolumn{1}{c}{ Punishment } & Presentase \\
\hline Teguran & $(27 \%)$ \\
\hline Surat Peringatan & $(22 \%)$ \\
\hline Pemutusan & $(29 \%)$ \\
Hubungan Keria &
\end{tabular}

Sumber: PT Glenmore Agung Nusantara

Atas dasar kaitan dari penelitian terdahulu maka peneliti ingin menganalisa hubungan yang terjadi antara reward, punishment, serta kinerja karyawan pada PT. Glenmore Agung Nusantara. Berikut merupakan tujuan penelitian ini :

1. Pengaruh reward terhadap kinerja karyawan pada PT. Glenmore Agung Nusantara

2. Pengaruh punishment terhadap kinerja karyawan pada PT. Glenmore Agung Nusantara

3. Pengaruh reward, punishment, terhadap kinerja karyawan pada PT. Glenmore Agung Nusantara.

Dengan dilakukannya penelitian ini, peneliti berharap dapat menggunakan judul penelitian tersebut untuk menambah wawasannya bagi peneliti selanjutnya. Serta dapat menyelesaikan masalah sesuai dengan judul penelitian ini. Bagi perusahaan sendiri diharapkan menjadi bahan penting bagi manajemen PT untuk 
mempertimbangkan dan memperoleh informasi. Glenmore Agung Nusantara meningkatkan kinerja karyawan.

\section{Metode Penelitian}

Penelitian ini dilakukan di PT. Glenmore Agung Nusantara terletak di Jalan Raya Kalimalang, Dusun Puseurjaya, Kecamatan Telukjambe Timur, Kabupaten Karawang, Jawa Barat. Studi akan dilakukan mulai November 2020 hingga Januari 2021. Tahap penelitian meliputi penyelidikan prapenelitian, pengujian instrumen penelitian, pengumpulan data penelitian, analisis data penelitian dan penulisan laporan penelitian.

Populasi yang digunakan dalam penelitian ini adalah seluruh karyawan PT. Glenmore Agung Nusantara yang berjumlah 54 karyawan. Hal ini sesuai dengan pendapat (Darma, Wicaksono, Sanica, \& Abiyasa, 2019)yang menyatakan sampling jenuh adalah teknik penentuan sampel dimana semua anggota populasi digunakan sebagai sampel. Sehingga penelitian ini mengumpulkan data dengan cara menyebarkan kuesioner kepada 54 responden yang telah disusun.

Instrumen penelitian yang digunakan adalah instrumen yang dikembangkan oleh peneliti sendiri. Peneliti menggunakan skala likert untuk menentukan masing-masing variabel yaitu variabel X1 (reward), X2 (hukuman) dan variabel Y (kinerja karyawan). Model hubungan antara ketiga variabel penelitian tersebut dapat digambarkan sebagai berikut:

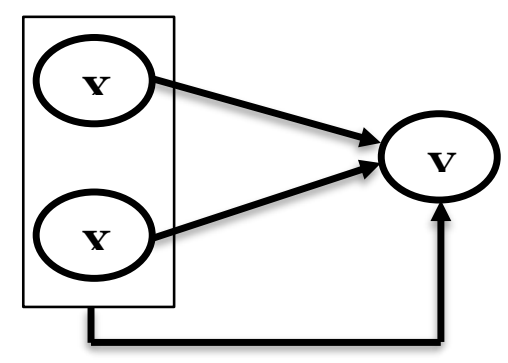

\section{Gambar 1}

Model Hubungan Antara Ketiga Variabel Penelitian

$$
\begin{aligned}
& \text { Keterangan: } \\
& \mathrm{X}_{1}=\text { Reward } \\
& \mathrm{X}_{2}=\text { Punishment } \\
& \mathrm{Y}=\text { Kinerja }
\end{aligned}
$$

Penelitian ini menggunakan asas pengukuran ordinal dengan skala numerical. Atas pengukuran yang mempunyai selisih yang jelas dan jarak yang sama pada skala. Penulisan jawaban kuesioner pada aras ordinal disusun berdasarkan pada skala numerical sehingga responden dapat memberikan penilaian pada setiap pernyataan yang di ukur dalam irama jenjang skala sebagai berikut.
Sangat Tidak Setuj
1
23
45
Sangat Setuju 
Pengujian selanjutnya adalah melakukan uji hipotesis atau uji statistik t yang bertujuan agar peneliti mengetahui seberapa besar pengaruh dari variabel independen secara individual dalam menjelaskan variasi variabel dependen dan dilanjutkan dengan melakukan uji parameter secara simultan atau uji F.

\section{Hasil dan Pembahasan}

\section{A. Uji t Variabel Reward, Variabel Punishment terhadap Variabel Kinerja}

Hasil uji t penelitian ini dapat dilihat pada tabel berikut :

\section{Tabel 5}

Hasil Perhitungan Uji t Kedua Variabel Independent

\begin{tabular}{|c|c|c|c|c|c|c|}
\hline & \multirow[b]{2}{*}{ Model } & \multicolumn{2}{|c|}{$\begin{array}{l}\text { Unstandardized } \\
\text { Coefficients }\end{array}$} & \multirow{2}{*}{$\begin{array}{c}\text { Standardized } \\
\text { Coefficients } \\
\text { Beta } \\
\end{array}$} & \multirow[b]{2}{*}{$\mathrm{t}$} & \multirow[b]{2}{*}{ Sig. } \\
\hline & & $\mathrm{B}$ & Std. Error & & & \\
\hline \multirow[t]{3}{*}{1} & (Constant) & -.235 & .360 & & -.653 & .516 \\
\hline & Reward & .342 & .099 & .235 & 3.448 & .001 \\
\hline & Punishment & 1.432 & .128 & .764 & 11.191 & .000 \\
\hline
\end{tabular}

Sumber: Hasil olah data menggunakan SPSS 26.0

Dari tabel diatas dapat dijelaskan sebagai berikut:

1. Dengan menggunakan hasil uji-t yang diperoleh SPSS diperoleh nilai t hitung variabel reward (X1) pada variabel kinerja (Y) sebesar 3,448, t tabel 1,675, kemudian 3,448>1,675, sehingga dapat disimpulkan bahwa variabel (X1) berpengaruh terhadap variabel pengaruh (Y) Berpengaruh positif dan signifikan. Hal ini juga sejalan dengan penelitian sebelumnya yang dilakukan oleh Husni et al. (2019), variabel reward yang dinilai oleh responden dapat berpengaruh positif dan signifikan terhadap kinerja karyawan Swiss-Belhotel Kendari yang ditunjukkan dengan nilai signifikan $0,000<0,05$.

2. Dengan menggunakan hasil uji-t yang diperoleh SPSS, nilai t hitung variabel penalti (X2) terhadap variabel kinerja (Y) sebesar 11,191, dan t tabel sebesar 1,675, kemudian 11,191> 1,675, sehingga dapat disimpulkan bahwa Variabel penalti (X2) berpengaruh terhadap variabel Kinerja (Y) Berpengaruh positif dan signifikan. Hal ini juga sejalan dengan penelitian sebelumnya yang dilakukan oleh Rendra Maulana Suryadilaga et al. (2016) yang menunjukkan bahwa variabel reward berpengaruh signifikan terhadap kinerja karyawan, atau dengan peningkatan reward maka kinerja akan meningkat secara signifikan. 
B. Uji F antara Variabel Reward, Variabel Punishment terhadap Variabel Kinerja

Hasil uji F penelitian ini dapat dilihat pada tabel berikut:

Tabel 6

Uji Simultan (Uji F) ANOVA ${ }^{a}$

\begin{tabular}{ccccccc}
\hline & Model & Sum of Squares & df & Mean Square & F & Sig. \\
\hline 1 & Regression & 5505.364 & 2 & 2752.682 & $\begin{array}{c}9677.70 \\
6\end{array}$ & $.000^{\mathrm{b}}$ \\
\cline { 2 - 7 } & & & & & \\
& Residual & 14.506 & 51 & .284 & \\
& Total & 5519.870 & 53 & & \\
\hline \multicolumn{6}{l}{ Sumber: Hasil olah data menggunakan SPSS 26.0 }
\end{tabular}

Berdasarkan tabel diatas diketahui bahwa nilai $F_{\text {hitung }}$ sebesar 9677,706 dan nilai $F_{\text {tabel }}$ sebesar 3,17 dari sampel sebanyak 54 dan dua variabel independen. Perbandingan antara nilai $F_{\text {tabel }}$ dan $F_{\text {hitung }}$ adalah 9677,706 > 3,17. Maka dapat disimpulkan bahwa adanya pengaruh yang positif dan signifikan antara variable Reward (X1) dan Punishment (X2) secara simultan terhadap variabel Kinerja (Y).

\section{Koefisien Determinasi}

Nilai koefisien determinasi penelitian dapat dilihat pada tabel berikut:

Tabel 7

Koefisien Determinasi

\begin{tabular}{ccccc}
\hline $\begin{array}{c}\text { Mode } \\
\mathrm{l}\end{array}$ & $\mathrm{R}$ & $\begin{array}{c}\mathrm{R} \\
\text { Square }\end{array}$ & $\begin{array}{c}\text { Adjusted R } \\
\text { Square }\end{array}$ & $\begin{array}{c}\text { Std. Error of the } \\
\text { Estimate }\end{array}$ \\
\hline 1 & $.999^{\mathrm{a}}$ & .997 & .997 & .533 \\
\hline \multicolumn{3}{l}{ Sumber: Hasil olah data menggunakan SPSS 26.0 }
\end{tabular}

Berdasarkan tabel diatas diketahui nilai Koefisien Determinasi sebesar 0,997. Hal ini dapat disimpulkan bahwa pengaruh variabel Reward dan variabel Punishment secara simultan mampu menjelaskan variabel kinerja sebesar 99,7\% sedangkan, sisanya sebesar $0,3 \%$ merupakan faktor-faktor lain yang tidak diteliti dalam penelitian ini.

D. Analisis Regresi Linear Berganda

Berdasarkan Hasil perhitungan uji t kedua variabel independent didapat persamaan Regresi Linear Berganda sebagai berikut:

$$
\begin{gathered}
\mathrm{Y}=(-235)+0,342 \mathrm{X}_{1}+1,432 \mathrm{X}_{2} \\
\text { Keterangan: } \\
\mathrm{X}_{1}=\text { Reward } \\
\mathrm{X}_{2}=\text { Punishment } \\
\mathrm{Y}=\text { Kinerja }
\end{gathered}
$$


Berikut penjelasannya:

1. Dari hasil uji t diperoleh nilai konstanta (koefisien intersep) sebesar -235. Hal ini menyatakan jika variabel Reward $\left(\mathrm{X}_{1}\right)$ dan variabel Punishment $\left(\mathrm{X}_{2}\right)$ nol maka nilai variabel Kinerja (Y) sebesar -235.

2. Nilai koefisien regresi variabel Reward $\left(\mathrm{X}_{1}\right)$ terhadap variabel Kinerja (Y) adalah sebesar 0,342. Hal ini menjelaskan jika variabel Reward $\left(\mathrm{X}_{1}\right)$ naik sebesar 1\%, akan meningkatkan variabel Kinerja (Y) sebesar 0,342, dengan asumsi variabel Punishment $\left(\mathrm{X}_{2}\right)$ dan konstanta dianggap tetap.

Hal ini dapat diartikan bahwa Reward yang diterima oleh karyawan baik secara finansial atau non finansial sudah sesuai maka akan berdampak positif terhadap kinerja karyawan tersebut. Berdasarkan hasil kuesioner yang sudah disebarkan kepada 54 responden menunjukkan bahwa Reward berada pada skala baik. Hal ini selaras dengan (Akhyadi, 2015) yang berpendapat bahwa Reward mampu meningkatkan kinerja seseorang, baik itu produktivitas, kedisiplinan, kreativitas, rasa tanggung jawab bahkan kepuasan keryawan tersebut. Penelitian ini juga sejalan dengan penelitian yang dilakukan oleh (Arfan Aruan, 2013) berjudul Pengaruh Pelatihan Kerja dan Reward Terhadap Kinerja Karyawan PT. Sucofindo (Persero) Surabaya. Dalam penelitiannya menyebutkan bahwa variabel Reward berpengaruh paling dominan terhadap kinerja dengan besar pengaruhnya adalah 37,21\%. Sedangkan untuk variabel pelatihan terhadap kinerja mempunyai pengaruh sebesar 23,72\%. Dalam jurnal yang ditulis oleh (Kusuma, 2018) mennyimpulkan bahwa Reward merupakan kunci utama dalam meningkatkan kinerja karyawan. Hal tersebut bertujuan agar karyawan bersemangat untu menyelesaikan beban tugas yang diberikan kepadanya.

3. Nilai koefisien regresi variabel Punishment $\left(\mathrm{X}_{2}\right)$ terhadap variabel Kinerja (Y) adalah sebesar1,432. Hal ini menjelaskan jika variabel Punishment $\left(\mathrm{X}_{2}\right)$ naik sebesar $1 \%$, maka hal tersebut akan meningkatkan variabel Kinerja (Y) sebesar 1,432 persen, dengan asumsi bahwa variabel Reward (X1) dianggap konstan atau tidak berubah.

Artinya, sanksi perusahaan terhadap karyawan akan berdampak positif terhadap kinerja setiap karyawan. Berdasarkan hasil kuesioner yang telah disebarkan kepada 54 responden, terlihat bahwa cakupan hukumannya sangat luas. Secara singkat Rivai \& Junani Sagala (2011) menuturkan bahwa pelatihan merupakan kegiatan untuk meningkatkan kinerja baik untuk saat ini maupun untuk masa medatang. Sedangkan pengembangan diberikan agar membantu karyawan untuk lebih peduli terhadap tanggung jawab pekerjaannya. Dalam jurnal penelitian yang dilakukan oleh Adhitomo Wirawan \& Ismi Nur Afani (2018) yang berjudul Pengaruh Reward dan Punishment terhadap Kinerja dan Motivasi Karyawan pada CV Media Kreasi Bangsa, dalam penelitiannya mereka mengatakan Variabel punishment 
berpengaruh positif terhadap kinerja hal ini dilihat dari t hitung $(5,309)$ lebih besar dari t tabel $(1,65)$ dengan tingkat signifikan $(0,000<0,05)$. Variabel punishment berpengaruh positif terhadap motivasi hal ini dilihat dari thitung $(3,587)$ lebih besar dari t tabel $(1,65)$ dengan tingkat signifikan $(0,000<$ 0,05). Penelitian ini juga sejalan dengan penelitian yang dilakokan oleh Kusuma (2015) yang berjudul Pengaruh Reward dan Pelatihan Terhadap Kinerja Studi pada Karyawan PT. PLN (Persero) Distribusi Jawa Timur Area Malang. Dalam penelitian tersebut menunjukkan adanya pengaruh signifikan secara simultan antara variabel pelatihan dan variabel Reward terhadap variabel kinerja karyawan.

\section{Kesimpulan}

Berdasarkan hasil penelitian menunjukkan bahwa reward antar PT berpengaruh positif dan signifikan terhadap kinerja karyawan. Glenmore Agung Nusantara (Glenmore Agung Nusantara). Semakin tinggi tingkat penghargaan karyawan, semakin tinggi pula tingkat kinerja karyawan tersebut. Ini akan berdampak baik bagi perusahaan.

Hal yang sama terjadi dengan variabel penalti pada variabel kinerja. Hukuman yang baik adalah dengan menetapkan karyawan yang diberikan perusahaan kepada karyawan, semakin tinggi tingkat kinerja karyawan tersebut. Hal ini tentunya akan berdampak positif bagi perusahaan.

Berdasarkan hasil perhitungan regresi linier berganda menunjukkan bahwa reward memiliki pengaruh yang lebih besar terhadap kinerja pegawai. Dengan cara ini perusahaan harus lebih memperhatikan kinerja karyawannya, jika ada karyawan yang berkinerja baik maka perusahaan dapat memberikan penghargaan kepada mereka.

Bagi peneliti selanjutnya, penulis merekomendasikan untuk mengeksplorasi faktor-faktor mana saja yang menyebabkan rendahnya motivasi kompensasi karyawan, dan pengaruhnya terhadap kinerja karyawan juga kecil. Faktor lain apa yang akan mempengaruhi karyawan untuk melakukan pelanggaran kerja, sehingga mendapat sanksi dari perusahaan. 


\section{BIBLIOGRAFI}

Chandra, Apridhika R. I. O. (2020). Kontribusi Bank Pembiayaan Rakyat Syariah (Bprs) Bandar Lampung Terhadap Perkembangan Usaha Mikro Di Kota Bandar Lampung Tahun 2018. Uin Raden Intan Lampung.

Darma, Gede Sri, Wicaksono, Katon, Sanica, I. Gede, \& Abiyasa, Agus Putu. (2019). Faktor Kompensasi Dan Strategi Gojek Dalam Meningkatkan Kepuasan Kerja Para Driver. Jmbi Unsrat (Jurnal Ilmiah Manajemen Bisnis Dan Inovasi Universitas Sam Ratulangi)., 6(3).

Febianti, Yopi Nisa. (2018). Peningkatan Motivasi Belajar Dengan Pemberian Reward And Punishment Yang Positif. Edunomic: Jurnal Ilmiah Pendidikan Ekonomi Fakultas Keguruan Dan Ilmu Pendidikan, 6(2), 93-102.

Nelizulfa, Aulia. (2018). Pengaruh Motivasi, Disiplin Kerja, Lingkungan Kerja Dan Kompensasi Terhadap Kinerja Karyawan (Studi Kasus Pada Pt. Jamu Air Mancur Karanganyar). Universitas Muhammadiyah Surakarta.

Pradnyani, Gusti Agung Ayu Intan, Rahmawati, Putu Indah, \& Suci, Ni Made. (2020). Pengaruh Reward Dan Punishment Terhadap Motivasi Kerja Karyawan Pada Cv Ayudya Tabanan Bali. Prospek: Jurnal Manajemen Dan Bisnis, 2(1), 21-30.

Soetjipto, Noer. (2017). Analisis Kinerja Pegawai Kecamatan Sidayu Kabupaten Gresik.

Suharyat, Yayat. (2009). Hubungan Antara Sikap, Minat Dan Perilaku Manusia. Jurnal Region, 1(3), 1-19.

Suparyadi, H. (2015). Manajemen Sumber Daya Manusia.

Suyanto, Hudi. (2018). Kedisiplinan Dan Kompensasi Dalam Mempengaruhi Kinerja Karyawan Pada Usaha Pariwisata Dynasti Water World Gkb Gresik. Jurnal Ekonomi Dan Kewirausahaan Kreatif, 3(2), 81-91.

Wulandari, Livya, Manullang, Rizal Ruben, \& Panjaitan, Fery. (2019). Analisis Strategi Pengingkatan Pendapatan Pada Usaha Mikro (Pedagang Kaki Lima Di Alun-Alun Taman Merdeka Kota Pangkalpinang. Jurnal Progresif Manajemen Bisnis, 6(2), 59-67. 